\title{
Exploring similarities in discrete facility location models with equality measures
}

Maria Barbati, University of Portsmouth, Faculty of Business and Law, Centre of Operations Research and Logistics (CORL), Portsmouth, United Kingdom.

Giuseppe Bruno, University of Naples "Federico II", Department of Industrial Engineering, Piazzale Tecchio 80, Naples, Italy

\section{Abstract}

There has been a number of discrete facility location models that deal with the use of some equality measures of the distances between the facility and the users. They have been used in order to guarantee a similar level of equity among the users that may be affected in a positive or in a good way from a facility. These models have been formulated trying to adapt equality measures taken from context different from the location one. This way, every measure is very specific to the particular application and it is not highlighted why a measure should be selected and what is the contribution to the equity distribution among the users that can provide. In this paper, we propose a Facility Location Problem (FLP) in which we have to locate a given number of facilities among a set of potential facilities, optimizing an equality measure. We propose a computational study in order to test the similarity and the differences of a good number of measures with more than a single facility to locate and we point out which measures produce similar results and how they depend on each other.

Keywords: Facility Location Problems, Equality Measures, Discrete Location. 


\section{Introduction}

Facility Location Problems (FLPs) consist in defining the position of a set of facilities, within a given location space, on the basis of a distribution of demand to be allocated to the facilities. The field is wide and evolving, and many FLPs can be formulated according to different criteria (e.g. number of facilities, facility/demand space, service competition, objectives, and application fields). For several applications it is appropriate to search for "fair" solutions with so-called "balancing objectives" i.e. objectives that balance the consequences of positioning facilities in order to guarantee a measure of equality in the distribution of costs and/or benefits (Eiselt and Laporte, 1995). More precisely, the level of equality in decision of choosing new sites for facilities can be evaluated comparing the consequences, both positive and negative, resulting for the groups that benefit or suffer it (Marsh and Shilling, 1994). In practice, if each group receives an equal share, then equality is guaranteed. Following Eiselt and Laporte (1995), in a FLP a balancing objective consists in a measure of the level of equality in the distribution of distances between users, located in demand points, and facilities.

Several papers deal with the problem of having fair solutions for FLPs. Typically, in the applications or case studies an equality measures is adopted as optimizing criterion without any justification of the choice or implication of it. For example, Burkey et al., (2012) uses the Gini coefficient to evaluate the equality of the distances for the patient to the nearest hospital. In the same perspective, Smith et al. (2013) proposes to use equity objective as weighted positive and negative deviation from a defined distance in hierarchical models for the location of facility in the public sector. Recently, the Gini coefficient has been used by Romero et al. (2016) to model the risk associated with the decision on the location and routing of a transportation railway for hazardous products.

Indeed, the majority of the papers list some measures that could or have been used in FLPs (i.e., Erkut 1993, Marsh and Shilling 1994, López-de-los-Mozos and Mesa 2001, López-De- 
Los-Mozos et al. 2008, Miyagawa 2014 and Kalcsics e al. 2015). They attempt to complete an exhaustive list of equality measures and to define some properties that show the differences among the several measures. Even so, these analyses present several weak points. First, all the measures have been adapted from other contexts and some of them have never been used in a FLP. Moreover, the properties that should help to choose which measure adopting are a transformation of general properties that have been taken from other fields (Marsh and Shilling, 1994) with only some attempts to particularize them for the location context (Barbati and Piccolo, 2016). Furthermore, even if theoretical properties have been proposed, these are related to only some of the measures as in Drezner et al. (2009) for the Gini coefficient and the maximum absolute deviation, or in Foul (2006) for the center measure. These theoretical results are related only to a single facility problem, without considering the case in which more facilities have to be located. In addition to focus on a single measure for a single facility location problem, they also deal with some particular configurations of the location space as in López-de-los-Mozos and Mesa (2001) for the maximum absolute deviation on a network or the variance problem in a discrete space as in Drezner and Drezner (2007) and Bruno et al. (2010).

We propose a computational study in order to evaluate existing correlations in using different equality measures in the context of FLPs. For small problems with just one facility to locate, it has been showed (Erkut, 1993) that applying different equality measures can bring to a different selection of the facility located. Thus, we aim to show that even when we have more facilities the choice of the equality measures is influencing the preferred position for the facilities to locate. In this sense, it is fundamental to understand if the use of different measures will imply that the set of facilities chosen is related or even the same when adopting a different measure. Furthermore, considerations on the computational efforts are required. Indeed, these two factors can determine which equality measure optimizing. 
The problem stands because several measures have been defined to describe the same concept of the equality of the distances from the facilities to the demand points. Other classical objectives do not present several measures for the same concept as for example the median problem that adopts as objective function the minimization of the sum of the distances (Hakimi, 1965).

Our study addresses these challenges by comparing a big number of measures, never being analyzed before in a computational study. The similarities of the selected position for the facilities and the different computational effort required are factors that influence the choice of the measure to optimize. For example, if a measure requires huge computational times and the optimal set of facilities is related to the one obtained adopting a different measure that takes less computational time, then this last measure could be preferred to the first one. On the other hand, if a measure is not related to other ones, then its adoption could be justified referring to some of the properties indicated in the literature (Barbati and Piccolo, 2016).

At the best of our knowledge, in only one paper equality measures have been compared in a computational study (Drezner, 2004); the authors found the best location of casualty collection points that are expected to become operational in case of a human-made or natural disaster with mass casualties, such as a high-magnitude earthquake. They suggested and analyzed five objective functions including the Variance and the Gini Coefficient. In addition, a multi-objective model has been proposed also applied to a scenario based on a large earthquake hitting Orange County (Drezner et al., 2006). The authors after having used the five different measures have concluded that some of them are not useful in this particular application without further exploiting why the measures were not appropriate or which was their grade of similarity. 
Let us justify our approach through the following comparison of two different applications of FLPs. In the first problem, we have to locate a new plant for the disposal of waste residual of a city. Let us suppose that this city is quite far from other cities. Our objective is obtaining equality in the distances from the households and the plant. In the second problem we have to determine the location of a given number of ambulances for each time cluster in which significant changes in demand pattern occur. In this case we want equality in the distances between the household and the ambulances. Both these problems have been studied in the literature adopting several different objectives (e.g., Erkut et al. 2008 and Rajagopalan et al. 2008). Clearly, a huge difference emerges in terms of the strategic decision. While the decision of the plant will be a long-term decision, the decision for the location of the ambulances is a short term decision that may require changes several times during the same day. This way, while for the location of the plant even measures with long computational times could be used, for the location of the ambulances measure with short computational times should be preferred. Moreover, the choice of the plant will have a huge impact on the population and it is likely that will cause concerns among the people; thus, it could require a better and more solid justification from the authorities. If the decision maker choses a very particular measure that implies a very particular position for the facility, not similar to other ones it is very difficult to justify the choice of that measure in order to guarantee equality by the decision maker. Whereas, in the case of the ambulances, given that their locations change quite often it is more unlikely to get obstruction from the population even a measure not related to others could be accepted. Another aspect of the decision concerns if the facility should be located inside or outside the city. In fact, it has been verified that a drawback of using equality measures is that solutions can be not efficient (e.g., Smith et al. 2013). In particular, if we assume that our city could be approximated with a uniform distribution of demand points, some measures are minimized when the facility is located outside the city, 
while other when the facility is located inside the city (Barbati and Piccolo 2016). In our example, the adoption of the first group of measures could be more useful for the first problem. Whereas, for the second problem, given that is a public and desirable service it is more useful to locate the ambulances inside the boundary of the city. Evidently, it remains the problem of choosing among the measures which one is most appropriate considering if we want a 'consistent' measure, in the sense that the results will be replicated adopting another measure. Moreover, we need to verify that the measure adopted can be calculated in adequate computational times. Our computational study permits to investigate all these aspects. We use an ad-hoc defined correlation coefficient to verify the similarities of the measures. Indeed, a correlation analysis can help to understand if the choice of the indicator would have resulted in a different outcome as showed in different fields such as social science (Kawachi and Kennedy, 1997), signal processing (Hu and Loizou, 2008) or economics (Geyer, 2010).

The remainder of the paper is organized as follows. In the next section, we illustrate the most meaningful measures selected from the literature. Afterwards we describe the characteristics of the performed empirical analysis. Then the obtained results are shown and discussed. Finally, conclusions and directions for further researches are drawn.

\section{Equality Measures for FLPs}

The list of possible measures has been described in three fundamental surveys on the topic (Erkut 1993, Marsh and Schilling 1994, Eiselt and Laporte 1995).

To provide useful indications about the appropriateness of measures to represent balancing objectives, in the literature different methodologies have been used. The first attempt in this 
field was performed by Halpern and Maimon (1983) who studied the behavior of four goals on a tree networks to determine the degree of agreement or disagreement between the analyzed measures. Marsh and Schilling (1994), as well as Eiselt and Laporte (1995), indicated some properties that a measure should reasonably satisfy. Erkut (1993) presented some axioms for the appropriateness of equality measures. He also calculated some statistics occurring among a set of four measures for a single location problem solved on tennode randomly generated instances on a square. Drezner et al. (2009) conducted a specific analysis on one of the most widely used equality measures, the Gini Coefficient, highlighting its behavior for a single facility problem with demand points uniformly distributed. Similar analysis has been proposed also for a new measure called the Quintile Share Ratio (Drezner et al. 2014). Recently Barbati and Piccolo (2016), proposed new properties that better specified the usefulness of every equality measure directly in the context of a location problem. Their analysis highlighted the typical behaviour of the most popular measures in presence of a uniform distribution of demand points in a regular circular location space.

Our paper aims at providing, in our opinion, a useful empirical sensitivity that may represent a support in the choice of an appropriate and consistent measure. In the following we describe the analysis performed on a significant number of the mentioned measures and we show and discuss the obtained results. 
Table 1 Equality Measures for FLP

\begin{tabular}{|c|c|c|c|c|c|}
\hline Code & Measure & Formulation & $\begin{array}{l}\text { Erkut } \\
\text { (1993) }\end{array}$ & $\begin{array}{l}\text { Marsh } \\
\text { Shilling } \\
(1994)\end{array}$ & $\begin{array}{c}\text { Eiselt } \\
\text { Laporte } \\
(1995)\end{array}$ \\
\hline CEN & Centre & $\max _{i \in I} d_{i}$ & • & • & $\bullet$ \\
\hline $\mathrm{RG}$ & Range & $\max _{i \in I} d_{i}-\min _{j \in I} d_{j}$ & & $\bullet$ & $\bullet$ \\
\hline MAD & $\begin{array}{l}\text { Mean Absolute } \\
\text { Deviation }\end{array}$ & $\sum_{i \in I}\left|d_{i}-\bar{d}\right|$ & - & - & - \\
\hline MD & $\begin{array}{l}\text { Maximum Absolute } \\
\text { Deviation }\end{array}$ & $\max _{i \in I}\left|d_{i}-\bar{d}\right|$ & • & • & • \\
\hline VAR & Variance & $\sum_{i \in I}\left(d_{i}-\bar{d}\right)^{2}$ & - & $\bullet$ & $\bullet$ \\
\hline$A D$ & Absolute Difference & $\sum_{c \in I} \sum_{d \in I}\left|d_{c}-d_{d}\right|$ & - & • & $\bullet$ \\
\hline SMDA & $\begin{array}{c}\text { Sum Maximum } \\
\text { DifferenceAbsolute }\end{array}$ & $\sum_{c \in I} \max _{d \in I}\left|d_{c}-d_{d}\right|$ & - & & \\
\hline MMDA & $\begin{array}{l}\text { Maximum Maximum } \\
\text { Difference Absolute }\end{array}$ & $\max _{i \in I} \max _{j \in I}\left|d_{i}-d_{j}\right|$ & $\bullet$ & & \\
\hline MSDA & $\begin{array}{c}\text { Maximum Sum } \\
\text { Difference Absolute }\end{array}$ & $\max _{c \in I} \sum_{d \in I}\left|d_{c}-d_{d}\right|$ & $\bullet$ & & \\
\hline LOGVAR & Variance of Logarithms & $\frac{1}{n} \sum_{i \in I}\left(\log d_{i}-\log \bar{d}\right)^{2}$ & & $\bullet$ & $\bullet$ \\
\hline GC & Gini Coefficient & $\frac{1}{2 \times n \times \bar{d}} \sum_{c \in I} \sum_{d \in I}\left|d_{c}-d_{d}\right|$ & $\bullet$ & $\bullet$ & $\bullet$ \\
\hline THE & $\begin{array}{l}\text { Theil's entropy } \\
\text { Coefficient }\end{array}$ & $\frac{1}{n d} \sum_{i \in I}\left(d_{i} \times \log d_{i}-\bar{d} \times \log \bar{d}\right)^{2}$ & & $\bullet$ & $\bullet$ \\
\hline SI & Schutz's Index & $\frac{1}{2 \times n \times \bar{d}} \sum_{i \in I}\left|d_{i}-\bar{d}\right|$ & & $\bullet$ & $\bullet$ \\
\hline VC & Coefficient of Variation & $\frac{1}{\bar{d}} \sum_{i \in I,}\left(d_{i}-\bar{d}\right)^{2}$ & & $\bullet$ & • \\
\hline ATK & Atkinson's coefficient & $1-n^{1 /(\delta-1)} \times\left[\sum_{i \in I}\left(\frac{d_{i}}{\bar{d}}\right)^{1-\delta}\right]^{1 /(1-\delta)}$ & & $\bullet$ & • \\
\hline
\end{tabular}




\section{The formulation of a p-FLP with equality objective}

Our analysis is oriented to determine relationships and correlations between pairs of measures when used as objective function to solve FLPs with balancing objectives. In other words, when we adopt a specific measure as objective function it could be useful to analyse what it would happen to the other measures.

To this aim we introduced a formulation of a mathematical model to describe a general problem of location of $p$ facilities with the objective of minimizing an equality measure. In order to do that, we considered the following notation:

$I \quad$ the set of $n$ demand points indexed by $i$;

$J \quad$ the set of $m$ potential facility locations indexed by $j$;

$d_{i j} \quad$ the distance between demand point $i$ and facility $j$;

$x_{i j} \quad$ a binary variable equal to 1 if the demand point $i$ is allocated to the facility $j$ ( 0 otherwise);

$y_{j} \quad$ a binary variable defined equal to 1 if in $j$ a facility is located ( 0 otherwise);

$\bar{d} \quad$ the average distance between demand points and the patronized facilities defined as $\sum_{i} d_{i j} \times x_{i j} / n ;$

$M \quad$ a large integer number such that $M \geq \max _{i \in I, j \in J} d_{i j}$.

The formulation of the mathematical model is:

$\min f_{k}\left(d_{i j}, x_{i j}\right)$

subject to:

$\sum_{j \in J} x_{i j}=1$

$\forall i \in I$

$y_{j}-x_{i j} \geq 0$

$\forall i \in I, \forall j \in J$

$\sum_{j \in J} y_{j}=p$

$\sum_{j \in J} d_{i j} x_{i j}+\left(M-d_{i j}\right) y_{j} \leq M$

$\forall i \in I, \forall j \in J$ 
$x_{i j}=0 / 1$

$\forall i \in I, \forall j \in J$

$y_{j}=0 / 1$

$\forall j \in J$

Constraints (2) assure that all the demand points are allocated. Constraints (3) indicate that a point may receive allocation only if it is active. Constraint (4) fixes the number of facilities to $p$. Constraints (5), as pointed out by Espejo et al. (2009), permit to allocate each demand point to the closest facility. Constraints (6) and (7) indicate that variables are binary.

The objective function $f_{\mathrm{k}}\left(d_{i j}, x_{i j}\right)$ represents a possible equality measure $k$ chosen to represent a balancing objective. In practice, it can be expressed by any of the measures indicated in Table 1 where each term $d_{i j}$ is replaced by $d_{i j} x_{i j}$. For instance, the expression of Variance (VAR) becomes $\sum_{i \in I}, \sum_{j \in J}\left(d_{i j} x_{i j}-\bar{d}\right)^{2}$.

The objective function $f_{\mathrm{k}}\left(d_{i j}, x_{i j}\right)$ is then linearized used the procedure proposed by Chang (2001). The linear versions of our model for the measures Schutz's Index, Coefficient Variation and Gini Coefficient are reported in the Appendix. For the measures Atkinson's Coefficient, Theil's Entropy Coefficient and Variance of Logartihms we use an enumeration procedure to find out the optimal location for the facilities to open.

\section{The empirical analysis}

To evaluate the degree of similarity between pairs of measures we solved the model considering each single equality measure. In particular, denoting with $v$, a label associated to a specific equality measure, for a given instance we indicate with $X_{v}^{*}$ the optimal solution obtained by solving the model (1) through (7) using objective function $v$ and with $f_{v}^{*}$ the corresponding value of the objective function solution $v$. Then we denote with $f_{u}^{v}$ the value of the measure $u$ associated with the solution $X_{v}^{*}$. For instance, if $u$ is the label of the Absolute Deviation $(A D)$ and $v$ that of the measure Mean Absolute Deviation (MAD), $f_{A D}^{M A D}$ represents 
the value of the Absolute Difference (AD) associated to optimal solution of the model (1) through (7), obtained by using Mean Absolute Deviation (MAD) as objective function.

This way considering a set of instances, for each pair $(v, u)$ of measures, it is possible to consider the two data sets: the first one representing the objective values $f_{v}^{*}$ of the solutions $X_{v}^{*}$; the second one the corresponding values, $f_{u}^{v}$. The analysis of these data sets provides interesting results in terms of relationship between each pair of measures.

The correlation coefficient $r_{u}^{v}$ can be viewed as a measure or the degree of similarity of the measures $(u, v)$ when a problem is solved. For example, in case $r_{u}^{v}=1$, it means that if we used $u$ or $v$ as objective functions, we would systematically find the same optimal solution. Then high values of $r_{u}^{v}$ indicate that by optimizing measure $v$ we would obtain values very close to the optimum ones for the measure $u$. In practice $r_{u}^{v}$ indicates how much a measure can be considered a good "proxy" for another measure. Furthermore, it has to be noticed that, due to its definition, generally the correlation coefficient $r_{u}^{v}$ is not symmetrical. In our analysis we considered randomly generated test problems in which the set $I$ of $n$ demand points and the set $J$ of $m$ potential facility locations have been positioned according to a uniform distribution in a unit square. Figure 1 shows an example of instance with $m=n=20$.

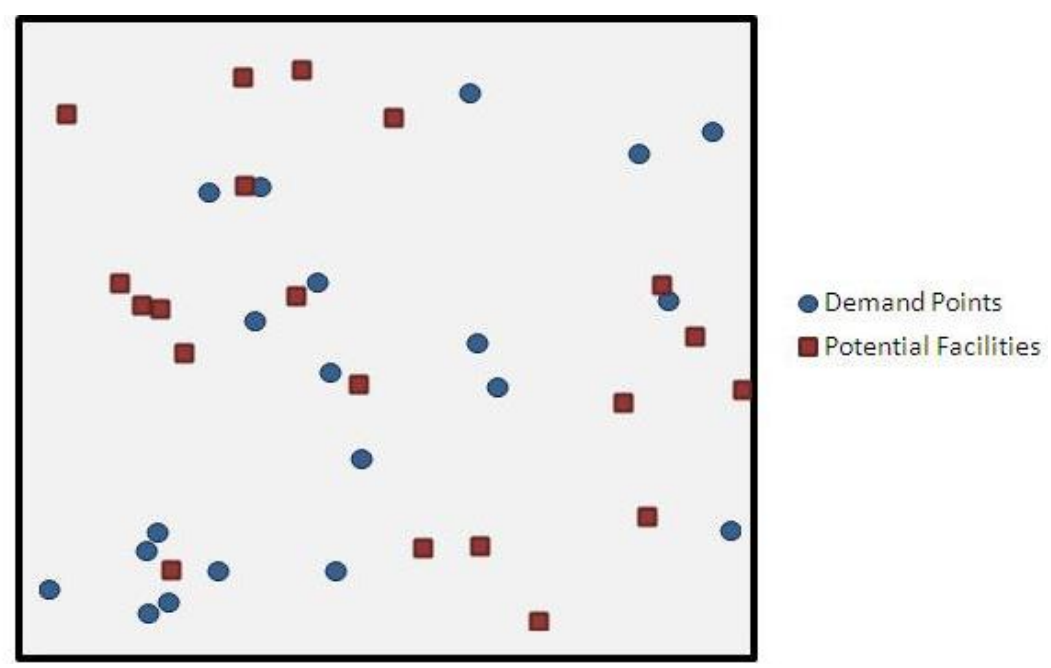

Fig. 1 An Example of randomly generated instance with $m=n=20$

For testing the similarities of the measures we considered two set of simulations: 
- $m=n=10$ and $m=n=20$ for 100 randomly generated instances assuming $p=2,3,4,5$ for the $10 \times 10$ problems and $p=2,4,6,8,10$ for the $20 \times 20$ problems.

- $m=n=20, m=n=40$ and $m=n=60$ for 100 randomly generated instances assuming $p=2$. For each pair of selected measures, we calculated:

- the number of instances out of $100, n_{u}^{v}$ (occurrences) in which it is obtained the same optimal solution for measures $v$ and $u$;

- the correlation coefficient $r_{u}^{v}$ i.e. for each pair $(v, u)$ of measures, we considered the correlation coefficient of a linear regression model between $f_{u}^{v}$ and $f_{v}^{*}$ obtained on the 100 instances.

\section{Analysis of the results}

We first proposed some considerations on the computational times to solve the model with the different measures. We solved our model for up to $m=n=60$ assuming $p=2$ and $p=10$. We used five random generated instances for each value of $m=n$. We reported in Table 2 the average computational times in seconds. We assumed a time limit of 2 hours. In the Table 2 $N / A$ means that we could not find an optimal solution for at least one of the instances within the time limit. The test was performed by using Cplex v 12.00 on a Pentium IV with 2.40 GigaHertz and 4.00 GigaBytes of RAM. Please note that two of the measures in Table 1 and included in Erkut (1993), have been excluded as they are directly proportional to the SMDA measure.

The analysis of the computational times suggests several considerations. First for small values of $m$ and $n$ the computational times are very similar for all the measures. The normalized measures (SI, VC, GC) have slightly larger computational times especially when $p=10$. Increasing the size of the instances means an increase in the computational times. Already with instances with $m=n=40$ we can see that for the normalized measures Cplex 
could not find the optimal solution within the time limit. Indeed, they seem to be very difficult to compute and only some relatively small instances can be solved. The not normalized measures require significant lower computational times. In particular, the measures $C E N$ and RG present very short computational times, even smaller when more facilities need to be located. In addition, for some of these measures some specific algorithm can be found in the literature (e.g., López-De-Los-Mozos et al. 2008) and the process may be faster. We do not use these algorithms because we want to compare under the same conditions all the measures.

Table 2 Computational times in seconds for randomly generated instances

\begin{tabular}{|c|c|c|c|c|c|c|}
\hline & \multicolumn{2}{|c|}{$\boldsymbol{m}=\boldsymbol{n = 2 0}$} & \multicolumn{2}{c|}{$\boldsymbol{m}=\mathbf{n = 4 0}$} & \multicolumn{2}{c|}{$\boldsymbol{m}=\boldsymbol{n}=\mathbf{6 0}$} \\
\hline & $\boldsymbol{p = 2}$ & $\boldsymbol{p = 1 0}$ & $\boldsymbol{p = 2}$ & $\boldsymbol{p = 1 0}$ & $\boldsymbol{p = 2}$ & $\boldsymbol{p = 1 0}$ \\
\hline CEN & $<1$ & $<1$ & 16 & 4 & 43 & 20 \\
\hline RG & 1 & 4 & 17 & 21 & 464 & 269 \\
\hline MAD & $<1$ & $<1$ & 24 & 264 & 166 & $\mathrm{~N} / \mathrm{A}$ \\
\hline VAR & 3 & $<1$ & 205 & 810 & 1206 & $\mathrm{~N} / \mathrm{A}$ \\
\hline MD & 3 & $<1$ & 7 & 6 & 143 & $\mathrm{~N} / \mathrm{A}$ \\
\hline AD & 6 & 2 & 46 & 2656 & 1123 & $\mathrm{~N} / \mathrm{A}$ \\
\hline SMDA & 13 & 3 & 56 & 767 & 1004 & $\mathrm{~N} / \mathrm{A}$ \\
\hline SI & 3 & 3 & 81 & $\mathrm{~N} / \mathrm{A}$ & 1033 & $\mathrm{~N} / \mathrm{A}$ \\
\hline VC & 4 & 22 & 130 & $\mathrm{~N} / \mathrm{A}$ & 1588 & $\mathrm{~N} / \mathrm{A}$ \\
\hline GC & 5 & 7 & 182 & $\mathrm{~N} / \mathrm{A}$ & 4022 & $\mathrm{~N} / \mathrm{A}$ \\
\hline
\end{tabular}


Table 3 Number of instances where two measures obtained the same optimal solution with $m=n=10$ and $p=2$

\begin{tabular}{|c|c|c|c|c|c|c|c|c|c|c|c|c|}
\hline & CEN & RG & MAD & VAR & MD & AD & SMDA & SI & VC & GC & LOGVAR & THE \\
\hline RG & 49 & & & & & & & & & & & \\
\hline MAD & 48 & 48 & & & & & & & & & & \\
\hline VAR & 42 & 58 & 75 & & & & & & & & & \\
\hline MD & 45 & 65 & 39 & 50 & & & & & & & & \\
\hline AD & 41 & 64 & 78 & 87 & 45 & & & & & & & \\
\hline SMDA & 45 & 81 & 63 & 77 & 62 & 71 & & & & & & \\
\hline SI & 12 & 28 & 50 & 40 & 25 & 40 & 62 & & & & & \\
\hline VC & 42 & 56 & 61 & 72 & 43 & 67 & 67 & 55 & & & & \\
\hline GC & 15 & 36 & 43 & 43 & 29 & 44 & 41 & 71 & 62 & & & \\
\hline LOGVAR & 12 & 39 & 40 & 50 & 34 & 47 & 44 & 55 & 61 & 63 & & \\
\hline THE & 17 & 37 & 64 & 54 & 29 & 54 & 49 & 75 & 64 & 57 & 49 & \\
\hline ATK & 11 & 42 & 39 & 50 & 38 & 39 & 45 & 50 & 62 & 59 & 90 & 44 \\
\hline
\end{tabular}

Table 4 Correlation coefficients for the $10 \times 10$ instances with $m=n=10$ and $p=2$

\begin{tabular}{|c|c|c|c|c|c|c|c|c|c|c|c|c|c|}
\hline & CEN & RG & MAD & VAR & MD & AD & SMDA & SI & VC & GC & LOGVAR & THE & ATK \\
\hline CEN & - & 0.68 & 0.59 & 0.63 & 0.61 & 0.62 & 0.67 & 0.16 & 0.40 & 0.14 & 0.08 & 0.39 & 0.05 \\
\hline RG & 0.60 & - & 0.80 & 0.87 & 0.97 & 0.94 & 0.97 & 0.62 & 0.83 & 0.66 & 0.54 & 0.74 & 0.58 \\
\hline MAD & 0.49 & 0.76 & - & 0.93 & 0.63 & 0.97 & 0.81 & 0.74 & 0.87 & 0.71 & 0.40 & 0.90 & 0.49 \\
\hline VAR & 0.59 & 0.89 & 0.95 & - & 0.79 & 0.97 & 0.93 & 0.65 & 0.88 & 0.65 & 0.52 & 0.84 & 0.50 \\
\hline MD & 0.58 & 0.95 & 0.75 & 0.80 & - & 0.82 & 0.93 & 0.60 & 0.78 & 0.61 & 0.53 & 0.72 & 0.58 \\
\hline AD & 0.57 & 0.84 & 0.97 & 0.97 & 0.67 & - & 0.86 & 0.71 & 0.89 & 0.71 & 0.45 & 0.88 & 0.52 \\
\hline SMDA & 0.60 & 0.97 & 0.88 & 0.94 & 0.92 & 0.93 & - & 0.66 & 0.87 & 0.68 & 0.58 & 0.81 & 0.59 \\
\hline SI & 0.10 & 0.45 & 0.47 & 0.40 & 0.38 & 0.48 & 0.44 & - & 0.78 & 0.97 & 0.40 & 0.87 & 0.50 \\
\hline VC & 0.39 & 0.83 & 0.83 & 0.79 & 0.76 & 0.85 & 0.85 & 0.85 & - & 0.86 & 0.63 & 0.94 & 0.57 \\
\hline GC & 0.18 & 0.51 & 0.54 & 0.48 & 0.42 & 0.56 & 0.50 & 0.95 & 0.80 & - & 0.68 & 0.84 & 0.64 \\
\hline LOGVAR & 0.12 & 0.54 & 0.55 & 0.51 & 0.49 & 0.56 & 0.56 & 0.91 & 0.81 & 0.93 & - & 0.83 & 0.97 \\
\hline THE & 0.35 & 0.68 & 0.81 & 0.70 & 0.59 & 0.80 & 0.69 & 0.90 & 0.90 & 0.88 & 0.34 & - & 0.43 \\
\hline ATK & 0.03 & 0.45 & 0.54 & 0.45 & 0.36 & 0.52 & 0.47 & 0.86 & 0.74 & 0.87 & 0.97 & 0.79 & - \\
\hline
\end{tabular}

Next, in Tables 3 we report the $n_{u}^{v}$ and in Table 4 the $r_{u}^{v}$ for the set of instances with $m=n=10$ and $p=2$. We highlight (in grey) the cases in which the minimum values of $n_{u}^{v}$ is at least 50 or $r_{u}^{v}$ is at least 0.80 . The values of $n_{u}^{v}$ are quite high for a significant number of pairs of 
measures, apart from the CEN measure. We have also very high values for the correlations coefficients, especially when considering normalized measures and in particular the measure THE. Nevertheless, the measure ATK, does not present high values of $r_{u}^{v}$ compared to the other normalized measures. The not normalized measures appear very high correlated among them.

To continue, results obtained on the randomly generated instances for the first set of simulation, are then summarized in Tables 5 up to 8 . In this case we only include the results deriving from the optimization of the model.

Table 5 Number of instances where two measures obtained the same optimal solution on $10 \mathrm{X} 10$ instances

\begin{tabular}{|c|c|c|c|c|c|c|c|c|c|c|c|}
\hline & & CEN & RG & MAD & VAR & MD & AD & SMDA & SI & VC & GC \\
\hline RG & $\begin{array}{l}\text { Max } \\
\text { Avrg } \\
\text { Min }\end{array}$ & $\begin{array}{l}55 \\
52 \\
49\end{array}$ & - & & & & & & & & \\
\hline MAD & $\begin{array}{l}\text { Max } \\
\text { Avrg } \\
\text { Min }\end{array}$ & $\begin{array}{l}56 \\
44 \\
37\end{array}$ & $\begin{array}{l}48 \\
35 \\
26\end{array}$ & - & & & & & & & \\
\hline VAR & $\begin{array}{l}\text { Max } \\
\text { Avrg } \\
\text { Min }\end{array}$ & $\begin{array}{l}59 \\
48 \\
42\end{array}$ & $\begin{array}{l}58 \\
45 \\
37\end{array}$ & $\begin{array}{l}75 \\
68 \\
63\end{array}$ & - & & & & & & \\
\hline MD & $\begin{array}{l}\text { Max } \\
\text { Avrg } \\
\text { Min }\end{array}$ & $\begin{array}{l}48 \\
46 \\
44 \\
\end{array}$ & $\begin{array}{l}65 \\
52 \\
40 \\
\end{array}$ & $\begin{array}{l}39 \\
30 \\
23\end{array}$ & $\begin{array}{l}50 \\
39 \\
32\end{array}$ & - & & & & & \\
\hline AD & $\begin{array}{l}\text { Max } \\
\text { Avrg } \\
\text { Min }\end{array}$ & $\begin{array}{l}56 \\
46 \\
40 \\
\end{array}$ & $\begin{array}{l}57 \\
43 \\
31\end{array}$ & $\begin{array}{l}78 \\
72 \\
66\end{array}$ & $\begin{array}{l}87 \\
79 \\
72 \\
\end{array}$ & $\begin{array}{l}45 \\
33 \\
26 \\
\end{array}$ & - & & & & \\
\hline SMDA & $\begin{array}{l}\text { Max } \\
\text { Avrg } \\
\text { Min }\end{array}$ & $\begin{array}{l}57 \\
50 \\
45 \\
\end{array}$ & $\begin{array}{l}71 \\
57 \\
49 \\
\end{array}$ & $\begin{array}{l}63 \\
52 \\
45 \\
\end{array}$ & $\begin{array}{l}77 \\
68 \\
61 \\
\end{array}$ & $\begin{array}{l}62 \\
52 \\
43 \\
\end{array}$ & $\begin{array}{l}71 \\
58 \\
49 \\
\end{array}$ & - & & & \\
\hline SI & $\begin{array}{l}\text { Max } \\
\text { Avrg } \\
\text { Min }\end{array}$ & $\begin{array}{l}28 \\
20 \\
12\end{array}$ & $\begin{array}{l}40 \\
36 \\
28\end{array}$ & $\begin{array}{l}52 \\
47 \\
41\end{array}$ & $\begin{array}{l}45 \\
42 \\
38 \\
\end{array}$ & $\begin{array}{l}25 \\
21 \\
16\end{array}$ & $\begin{array}{l}47 \\
43 \\
38\end{array}$ & $\begin{array}{l}38 \\
36 \\
34 \\
\end{array}$ & - & & \\
\hline VC & $\begin{array}{l}\text { Max } \\
\text { Avrg } \\
\text { Min }\end{array}$ & $\begin{array}{l}59 \\
48 \\
42\end{array}$ & $\begin{array}{l}63 \\
60 \\
56\end{array}$ & $\begin{array}{l}63 \\
56 \\
47\end{array}$ & $\begin{array}{l}72 \\
67 \\
60\end{array}$ & $\begin{array}{l}43 \\
36 \\
31\end{array}$ & $\begin{array}{l}67 \\
63 \\
52\end{array}$ & $\begin{array}{l}67 \\
61 \\
58\end{array}$ & $\begin{array}{l}63 \\
57 \\
54\end{array}$ & - & \\
\hline GC & $\begin{array}{l}\text { Max } \\
\text { Avrg } \\
\text { Min }\end{array}$ & $\begin{array}{l}28 \\
20 \\
15\end{array}$ & $\begin{array}{l}45 \\
42 \\
36\end{array}$ & $\begin{array}{l}48 \\
42 \\
37\end{array}$ & $\begin{array}{l}43 \\
41 \\
38\end{array}$ & $\begin{array}{l}29 \\
24 \\
20\end{array}$ & $\begin{array}{l}45 \\
43 \\
39\end{array}$ & $\begin{array}{l}41 \\
39 \\
37\end{array}$ & $\begin{array}{l}75 \\
72 \\
71\end{array}$ & $\begin{array}{l}63 \\
62 \\
61\end{array}$ & - \\
\hline
\end{tabular}


Table 6 Number of instances where two measures obtained the same optimal solution on 20X20 instances

\begin{tabular}{|c|c|c|c|c|c|c|c|c|c|c|c|}
\hline & & CEN & RG & MAD & VAR & MD & $A D$ & SMDA & SI & VC & GC \\
\hline RG & $\begin{array}{c}\text { Max } \\
\text { Avrg } \\
\text { Min }\end{array}$ & $\begin{array}{l}65 \\
50 \\
36\end{array}$ & - & & & & & & & & \\
\hline MAD & $\begin{array}{c}\text { Max } \\
\text { Avrg } \\
\text { Min }\end{array}$ & $\begin{array}{l}59 \\
33 \\
14\end{array}$ & $\begin{array}{c}20 \\
7 \\
2\end{array}$ & - & & & & & & & \\
\hline VAR & $\begin{array}{c}\text { Max } \\
\text { Avrg } \\
\text { Min }\end{array}$ & $\begin{array}{l}73 \\
44 \\
22\end{array}$ & $\begin{array}{c}34 \\
16 \\
4\end{array}$ & $\begin{array}{l}57 \\
45 \\
39\end{array}$ & - & & & & & & \\
\hline MD & $\begin{array}{c}\text { Max } \\
\text { Avrg } \\
\text { Min }\end{array}$ & $\begin{array}{l}67 \\
46 \\
30\end{array}$ & $\begin{array}{c}50 \\
23 \\
3\end{array}$ & $\begin{array}{c}18 \\
6 \\
1\end{array}$ & $\begin{array}{c}32 \\
13 \\
2\end{array}$ & - & & & & & \\
\hline AD & $\begin{array}{c}\text { Max } \\
\text { Avrg } \\
\text { Min }\end{array}$ & $\begin{array}{l}71 \\
42 \\
20\end{array}$ & $\begin{array}{l}47 \\
36 \\
30\end{array}$ & $\begin{array}{l}66 \\
54 \\
46\end{array}$ & $\begin{array}{l}80 \\
71 \\
60\end{array}$ & $\begin{array}{c}24 \\
10 \\
2\end{array}$ & - & & & & \\
\hline SMDA & $\begin{array}{c}\text { Max } \\
\text { Avrg } \\
\text { Min }\end{array}$ & $\begin{array}{l}76 \\
52 \\
33\end{array}$ & $\begin{array}{l}71 \\
69 \\
65\end{array}$ & $\begin{array}{l}35 \\
23 \\
13\end{array}$ & $\begin{array}{l}57 \\
41 \\
29\end{array}$ & $\begin{array}{c}52 \\
24 \\
6\end{array}$ & $\begin{array}{l}47 \\
34 \\
24\end{array}$ & - & & & \\
\hline SI & $\begin{array}{l}\text { Max } \\
\text { Avrg } \\
\text { Min }\end{array}$ & $\begin{array}{c}28 \\
13 \\
4\end{array}$ & $\begin{array}{c}11 \\
5 \\
3\end{array}$ & $\begin{array}{l}32 \\
27 \\
23\end{array}$ & $\begin{array}{l}24 \\
20 \\
16\end{array}$ & $\begin{array}{c}11 \\
4 \\
1\end{array}$ & $\begin{array}{l}31 \\
23 \\
19\end{array}$ & $\begin{array}{c}19 \\
14 \\
8\end{array}$ & - & & \\
\hline VC & $\begin{array}{c}\text { Max } \\
\text { Avrg } \\
\text { Min }\end{array}$ & $\begin{array}{l}73 \\
44 \\
22\end{array}$ & $\begin{array}{c}32 \\
15 \\
6\end{array}$ & $\begin{array}{l}42 \\
32 \\
22\end{array}$ & $\begin{array}{l}63 \\
51 \\
40\end{array}$ & $\begin{array}{c}26 \\
11 \\
2\end{array}$ & $\begin{array}{l}59 \\
46 \\
35\end{array}$ & $\begin{array}{l}45 \\
36 \\
30\end{array}$ & $\begin{array}{l}39 \\
33 \\
26\end{array}$ & - & \\
\hline GC & $\begin{array}{c}\text { Max } \\
\text { Avrg } \\
\text { Min }\end{array}$ & $\begin{array}{c}33 \\
15 \\
4\end{array}$ & $\begin{array}{c}18 \\
8 \\
4\end{array}$ & $\begin{array}{l}31 \\
24 \\
19\end{array}$ & $\begin{array}{l}33 \\
28 \\
22\end{array}$ & $\begin{array}{c}17 \\
5 \\
1\end{array}$ & $\begin{array}{l}40 \\
30 \\
23\end{array}$ & $\begin{array}{c}21 \\
17 \\
9\end{array}$ & $\begin{array}{l}63 \\
53 \\
46\end{array}$ & $\begin{array}{l}55 \\
53 \\
50\end{array}$ & \\
\hline
\end{tabular}

Table 7 Correlation coefficients for the $10 \times 10$ instances

\begin{tabular}{|c|c|c|c|c|c|c|c|c|c|c|c|}
\hline & & CEN & $\mathbf{R G}$ & MAD & VAR & MD & $A D$ & SMDA & SI & VC & GC \\
\hline CEN & $\begin{array}{l}\text { Max } \\
\text { Avrg } \\
\text { Min }\end{array}$ & & $\begin{array}{l}0.93 \\
0.83 \\
0.68\end{array}$ & $\begin{array}{l}0.88 \\
0.74 \\
0.59\end{array}$ & $\begin{array}{l}0.89 \\
0.77 \\
0.63\end{array}$ & $\begin{array}{l}0.91 \\
0.80 \\
0.61\end{array}$ & $\begin{array}{l}0.90 \\
0.78 \\
0.62\end{array}$ & $\begin{array}{l}0.94 \\
0.83 \\
0.67\end{array}$ & $\begin{array}{l}0.43 \\
0.26 \\
0.08\end{array}$ & $\begin{array}{l}0.79 \\
0.60 \\
0.40\end{array}$ & $\begin{array}{l}0.43 \\
0.27 \\
0.11\end{array}$ \\
\hline $\mathbf{R G}$ & $\begin{array}{l}\text { Max } \\
\text { Avrg } \\
\text { Min }\end{array}$ & $\begin{array}{l}0.81 \\
0.68 \\
0.60\end{array}$ & - & $\begin{array}{l}0.91 \\
0.86 \\
0.80\end{array}$ & $\begin{array}{l}0.94 \\
0.91 \\
0.87\end{array}$ & $\begin{array}{l}0.99 \\
0.97 \\
0.92\end{array}$ & $\begin{array}{l}0.96 \\
0.96 \\
0.94\end{array}$ & $\begin{array}{l}0.99 \\
0.98 \\
0.97\end{array}$ & $\begin{array}{l}0.62 \\
0.52 \\
0.45\end{array}$ & $\begin{array}{l}0.83 \\
0.81 \\
0.79 \\
\end{array}$ & $\begin{array}{l}0.66 \\
0.55 \\
0.48\end{array}$ \\
\hline MAD & $\begin{array}{l}\text { Max } \\
\text { Avrg } \\
\text { Min }\end{array}$ & $\begin{array}{l}0.71 \\
0.60 \\
0.49\end{array}$ & $\begin{array}{l}0.87 \\
0.79 \\
0.75\end{array}$ & - & $\begin{array}{l}0.95 \\
0.93 \\
0.91\end{array}$ & $\begin{array}{l}0.79 \\
0.71 \\
0.63\end{array}$ & $\begin{array}{l}0.98 \\
0.97 \\
0.96\end{array}$ & $\begin{array}{l}0.90 \\
0.85 \\
0.81\end{array}$ & $\begin{array}{l}0.74 \\
0.60 \\
0.51\end{array}$ & $\begin{array}{l}0.87 \\
0.82 \\
0.79\end{array}$ & $\begin{array}{l}0.71 \\
0.59 \\
0.52\end{array}$ \\
\hline VAR & $\begin{array}{l}\text { Max } \\
\text { Avrg } \\
\text { Min }\end{array}$ & $\begin{array}{l}0.77 \\
0.65 \\
0.58 \\
\end{array}$ & $\begin{array}{l}0.94 \\
0.92 \\
0.89 \\
\end{array}$ & $\begin{array}{l}0.96 \\
0.95 \\
0.95 \\
\end{array}$ & - & $\begin{array}{l}0.88 \\
0.85 \\
0.79 \\
\end{array}$ & $\begin{array}{l}0.98 \\
0.98 \\
0.97 \\
\end{array}$ & $\begin{array}{l}0.96 \\
0.95 \\
0.93 \\
\end{array}$ & $\begin{array}{l}0.65 \\
0.54 \\
0.45 \\
\end{array}$ & $\begin{array}{l}0.88 \\
0.85 \\
0.82 \\
\end{array}$ & $\begin{array}{l}0.65 \\
0.55 \\
0.45 \\
\end{array}$ \\
\hline MD & $\begin{array}{l}\text { Max } \\
\text { Avrg } \\
\text { Min }\end{array}$ & $\begin{array}{l}0.81 \\
0.71 \\
0.58\end{array}$ & $\begin{array}{l}0.97 \\
0.97 \\
0.95\end{array}$ & $\begin{array}{l}0.86 \\
0.80 \\
0.75\end{array}$ & $\begin{array}{l}0.89 \\
0.86 \\
0.80\end{array}$ & - & $\begin{array}{l}0.90 \\
0.86 \\
0.82\end{array}$ & $\begin{array}{l}0.96 \\
0.94 \\
0.93\end{array}$ & $\begin{array}{l}0.60 \\
0.46 \\
0.34\end{array}$ & $\begin{array}{l}0.82 \\
0.76 \\
0.71\end{array}$ & $\begin{array}{l}0.61 \\
0.50 \\
0.37\end{array}$ \\
\hline AD & $\begin{array}{l}\text { Max } \\
\text { Avrg } \\
\text { Min }\end{array}$ & $\begin{array}{l}0.74 \\
0.64 \\
0.57\end{array}$ & $\begin{array}{l}0.92 \\
0.89 \\
0.84\end{array}$ & $\begin{array}{l}0.98 \\
0.97 \\
0.96\end{array}$ & $\begin{array}{l}0.97 \\
0.97 \\
0.97\end{array}$ & $\begin{array}{l}0.82 \\
0.78 \\
0.67\end{array}$ & - & $\begin{array}{l}0.93 \\
0.91 \\
0.86\end{array}$ & $\begin{array}{l}0.71 \\
0.59 \\
0.52\end{array}$ & $\begin{array}{l}0.89 \\
0.86 \\
0.84\end{array}$ & $\begin{array}{l}0.71 \\
0.60 \\
0.52\end{array}$ \\
\hline SMDA & $\begin{array}{l}\text { Max } \\
\text { Avrg } \\
\text { Min }\end{array}$ & $\begin{array}{l}0.81 \\
0.68 \\
0.60\end{array}$ & $\begin{array}{l}0.99 \\
0.98 \\
0.97\end{array}$ & $\begin{array}{l}0.95 \\
0.91 \\
0.88\end{array}$ & $\begin{array}{l}0.96 \\
0.96 \\
0.94\end{array}$ & $\begin{array}{l}0.96 \\
0.94 \\
0.92\end{array}$ & $\begin{array}{l}0.97 \\
0.96 \\
0.93\end{array}$ & - & $\begin{array}{l}0.66 \\
0.54 \\
0.46\end{array}$ & $\begin{array}{l}0.87 \\
0.85 \\
0.82\end{array}$ & $\begin{array}{l}0.68 \\
0.56 \\
0.48 \\
\end{array}$ \\
\hline SI & $\begin{array}{l}\text { Max } \\
\text { Avrg } \\
\text { Min }\end{array}$ & $\begin{array}{l}0.21 \\
0.12 \\
0.08\end{array}$ & $\begin{array}{l}0.49 \\
0.44 \\
0.41\end{array}$ & $\begin{array}{l}0.63 \\
0.55 \\
0.47\end{array}$ & $\begin{array}{l}0.49 \\
0.44 \\
0.40\end{array}$ & $\begin{array}{l}0.47 \\
0.39 \\
0.35\end{array}$ & $\begin{array}{l}0.60 \\
0.53 \\
0.48\end{array}$ & $\begin{array}{l}0.53 \\
0.46 \\
0.43\end{array}$ & - & $\begin{array}{l}0.79 \\
0.77 \\
0.73\end{array}$ & $\begin{array}{l}0.97 \\
0.97 \\
0.96\end{array}$ \\
\hline VC & $\begin{array}{l}\text { Max } \\
\text { Avrg } \\
\text { Min } \\
\end{array}$ & $\begin{array}{l}0.51 \\
0.40 \\
0.33 \\
\end{array}$ & $\begin{array}{l}0.84 \\
0.82 \\
0.78\end{array}$ & $\begin{array}{l}0.89 \\
0.85 \\
0.83\end{array}$ & $\begin{array}{l}0.88 \\
0.84 \\
0.79\end{array}$ & $\begin{array}{l}0.79 \\
0.76 \\
0.73 \\
\end{array}$ & $\begin{array}{l}0.90 \\
0.87 \\
0.85\end{array}$ & $\begin{array}{l}0.87 \\
0.85 \\
0.82 \\
\end{array}$ & $\begin{array}{l}0.85 \\
0.81 \\
0.79\end{array}$ & - & $\begin{array}{l}0.86 \\
0.84 \\
0.82\end{array}$ \\
\hline GC & $\begin{array}{l}\text { Max } \\
\text { Avrg } \\
\text { Min }\end{array}$ & $\begin{array}{l}0.26 \\
0.18 \\
0.11 \\
\end{array}$ & $\begin{array}{l}0.56 \\
0.52 \\
0.45 \\
\end{array}$ & $\begin{array}{l}0.64 \\
0.57 \\
0.54 \\
\end{array}$ & $\begin{array}{l}0.52 \\
0.49 \\
0.48 \\
\end{array}$ & $\begin{array}{l}0.48 \\
0.43 \\
0.38 \\
\end{array}$ & $\begin{array}{l}0.64 \\
0.58 \\
0.56 \\
\end{array}$ & $\begin{array}{l}0.56 \\
0.51 \\
0.47 \\
\end{array}$ & $\begin{array}{l}0.97 \\
0.96 \\
0.95\end{array}$ & $\begin{array}{l}0.83 \\
0.82 \\
0.80 \\
\end{array}$ & - \\
\hline
\end{tabular}


More precisely, Tables 5 and 6 indicate $n_{u}^{v}$ respectively for problems $10 \times 10$ and 20x20 reporting the minimum ( $\mathrm{min}$ ), the average (avrg) and the maximum (max) value considering the different assumed values of $p$. In Tables 7 and 8 we show the obtained values of $r_{u}^{v}$, with the same meaning for min, avrg and max.

Table 8 Correlation coefficients for the 20x20 instances

\begin{tabular}{|c|c|c|c|c|c|c|c|c|c|c|c|}
\hline & & CEN & $\mathbf{R G}$ & MAD & VAR & MD & AD & SMDA & SI & VC & GC \\
\hline \multirow[t]{3}{*}{ CEN } & Max & & 0.98 & 0.92 & 0.94 & 0.96 & 0.94 & 0.97 & 0.56 & 0.85 & 0.60 \\
\hline & Avrg & - & 0.95 & 0.86 & 0.90 & 0.90 & 0.89 & 0.94 & 0.52 & 0.81 & 0.55 \\
\hline & Min & & 0.88 & 0.77 & 0.83 & 0.77 & 0.82 & 0.87 & 0.49 & 0.73 & 0.48 \\
\hline \multirow[t]{3}{*}{ RG } & Max & 0.91 & & 0.89 & 0.94 & 0.99 & 0.96 & 0.99 & 0.71 & 0.91 & 0.73 \\
\hline & Avrg & 0.75 & - & 0.81 & 0.90 & 0.97 & 0.88 & 0.98 & 0.58 & 0.82 & 0.62 \\
\hline & Min & 0.59 & & 0.67 & 0.81 & 0.92 & 0.78 & 0.95 & 0.43 & 0.72 & 0.51 \\
\hline \multirow[t]{3}{*}{ MAD } & Max & 0.75 & 0.78 & & 0.95 & 0.73 & 0.99 & 0.83 & 0.66 & 0.87 & 0.67 \\
\hline & Avrg & 0.60 & 0.69 & - & 0.92 & 0.61 & 0.97 & 0.76 & 0.64 & 0.83 & 0.63 \\
\hline & Min & 0.40 & 0.54 & & 0.87 & 0.42 & 0.94 & 0.63 & 0.62 & 0.78 & 0.59 \\
\hline \multirow[t]{3}{*}{ VAR } & Max & 0.84 & 0.91 & 0.95 & & 0.88 & 0.98 & 0.95 & 0.68 & 0.90 & 0.68 \\
\hline & Avrg & 0.69 & 0.86 & 0.92 & - & 0.78 & 0.98 & 0.92 & 0.58 & 0.87 & 0.61 \\
\hline & Min & 0.53 & 0.80 & 0.87 & & 0.67 & 0.97 & 0.87 & 0.52 & 0.86 & 0.54 \\
\hline \multirow[t]{3}{*}{ MD } & Max & 0.89 & 0.99 & 0.94 & 0.96 & & 0.96 & 0.99 & 0.63 & 0.90 & 0.65 \\
\hline & Avrg & 0.73 & 0.98 & 0.85 & 0.91 & - & 0.90 & 0.97 & 0.56 & 0.83 & 0.60 \\
\hline & Min & 0.56 & 0.96 & 0.73 & 0.82 & & 0.81 & 0.94 & 0.53 & 0.75 & 0.58 \\
\hline \multirow[t]{3}{*}{ AD } & Max & 0.78 & 0.86 & 0.98 & 0.97 & 0.77 & & 0.87 & 0.69 & 0.88 & 0.67 \\
\hline & Avrg & 0.63 & 0.77 & 0.96 & 0.97 & 0.67 & - & 0.83 & 0.62 & 0.86 & 0.63 \\
\hline & Min & 0.44 & 0.69 & 0.92 & 0.95 & 0.57 & & 0.77 & 0.54 & 0.83 & 0.56 \\
\hline \multirow[t]{3}{*}{ SMDA } & Max & 0.89 & 0.99 & 0.90 & 0.95 & 0.97 & 0.95 & & 0.63 & 0.91 & 0.65 \\
\hline & Avrg & 0.72 & 0.97 & 0.85 & 0.94 & 0.94 & 0.92 & - & 0.54 & 0.85 & 0.58 \\
\hline & Min & 0.46 & 0.95 & 0.80 & 0.92 & 0.90 & 0.90 & & 0.43 & 0.81 & 0.48 \\
\hline \multirow[t]{3}{*}{ SI } & Max & 0.47 & 0.65 & 0.71 & 0.69 & 0.67 & 0.70 & 0.70 & & 0.87 & 0.98 \\
\hline & Avrg & 0.25 & 0.49 & 0.59 & 0.54 & 0.46 & 0.58 & 0.52 & - & 0.80 & 0.97 \\
\hline & Min & 0.03 & 0.31 & 0.44 & 0.36 & 0.23 & 0.43 & 0.32 & & 0.70 & 0.96 \\
\hline \multirow[t]{3}{*}{ VC } & Max & 0.73 & 0.89 & 0.91 & 0.92 & 0.84 & 0.93 & 0.92 & 0.86 & & 0.88 \\
\hline & Avrg & 0.44 & 0.78 & 0.84 & 0.86 & 0.70 & 0.87 & 0.83 & 0.83 & - & 0.86 \\
\hline & Min & 0.16 & 0.68 & 0.78 & 0.80 & 0.55 & 0.81 & 0.74 & 0.80 & & 0.85 \\
\hline \multirow[t]{3}{*}{ GC } & Max & 0.37 & 0.61 & 0.69 & 0.67 & 0.57 & 0.69 & 0.65 & 0.98 & 0.89 & \multirow{3}{*}{. } \\
\hline & Avrg & 0.19 & 0.49 & 0.54 & 0.51 & 0.44 & 0.55 & 0.51 & 0.97 & 0.82 & \\
\hline & Min & 0.17 & 0.28 & 0.37 & 0.30 & 0.22 & 0.36 & 0.29 & 0.96 & 0.71 & \\
\hline
\end{tabular}


The analysis of the results suggests various comments that we synthesize in the following points.

- Even if, for smaller problems (10x10), the values of $n_{u}^{v}$ are quite high for a significant number of pairs of measures, they tend to decrease in not negligible way with larger problems. However it is immediate to notice the existence of various pairs of measures whose optimal solutions rarely coincide.

- Correlation values are very high among pairs of not-normalized measures (RG, MAD, VAR, MD, AD, SMDA) and pairs of normalized measures (SI, VC, GC). This means that even when the coincidence of optimal solutions is not frequent, their values may be very close. In any case, high correlations between these pairs of measures may suggest that a fundamental choice in the selection of the measure to be adopted lies in the distinction between not-normalized and normalized measures.

- The Center measure (CEN) appears very weakly correlated with all the other measures. This result seems to contradict the opinion of some researchers (e.g., Hodgart 1980, Lei 2016 ) which sustained that one method to assure equity is improving the condition of those who are worst-off.

- Among the selected measures, the Coefficient of Variation (VC) shows a very high correlation with all the other measures, apart from the CEN.

In the second part of our computational study we consider bigger instance with up $m=n=60$ and $p=2$. In Tables 9, 10 and 11 we reported the values of the $r_{u}^{v}$. We can notice that the results are showing quite interesting aspects. 
Table 9 Correlation coefficients for the 20x0 instances

\begin{tabular}{|c|c|c|c|c|c|c|c|c|c|c|}
\hline & CEN & RG & MAD & VAR & MD & AD & SMDA & SI & VC & GC \\
\hline CEN & - & 0.50 & 0.36 & 0.50 & 0.49 & 0.46 & 0.53 & -0.04 & 0.28 & -0.06 \\
\hline RG & 0.55 & - & 0.63 & 0.88 & 0.97 & 0.78 & 0.99 & 0.48 & 0.82 & 0.45 \\
\hline MAD & 0.35 & 0.66 & - & 0.95 & 0.64 & 0.98 & 0.76 & 0.57 & 0.82 & 0.55 \\
\hline VAR & 0.32 & 0.84 & 0.96 & - & 0.82 & 0.99 & 0.92 & 0.40 & 0.89 & 0.45 \\
\hline MD & 0.44 & 0.94 & 0.60 & 0.78 & - & 0.66 & 0.95 & 0.44 & 0.76 & 0.48 \\
\hline AD & 0.40 & 0.82 & 0.99 & 0.99 & 0.78 & - & 0.89 & 0.50 & 0.88 & 0.53 \\
\hline SMDA & 0.48 & 0.98 & 0.76 & 0.94 & 0.96 & 0.86 & - & 0.49 & 0.88 & 0.51 \\
\hline SI & 0.28 & 0.52 & 0.74 & 0.62 & 0.51 & 0.65 & 0.58 & - & 0.86 & 0.99 \\
\hline VC & 0.36 & 0.82 & 0.94 & 0.95 & 0.83 & 0.94 & 0.92 & 0.81 & - & 0.88 \\
\hline GC & 0.26 & 0.58 & 0.75 & 0.66 & 0.58 & 0.68 & 0.65 & 0.99 & 0.91 & - \\
\hline
\end{tabular}

Table 10 Correlation coefficients for the $40 \times 40$ instances

\begin{tabular}{|l|l|l|l|l|l|l|l|l|l|l|}
\hline & CEN & RG & MAD & VAR & MD & AD & SMDA & SI & VC & GC \\
\hline CEN & - & 0.58 & 0.37 & 0.44 & 0.44 & 0.43 & 0.56 & -0.07 & 0.17 & -0.08 \\
\hline RG & 0.44 & - & 0.45 & 0.59 & 0.81 & 0.45 & 0.91 & 0.29 & 0.51 & 0.35 \\
\hline MAD & 0.29 & 0.38 & - & 0.84 & 0.28 & 0.94 & 0.48 & 0.66 & 0.70 & 0.59 \\
\hline VAR & 0.27 & 0.49 & 0.90 & - & 0.45 & 0.98 & 0.69 & 0.65 & 0.85 & 0.63 \\
\hline MD & 0.52 & 0.94 & 0.50 & 0.66 & - & 0.63 & 0.90 & 0.33 & 0.56 & 0.40 \\
\hline AD & 0.19 & 0.31 & 0.95 & 0.97 & 0.20 & - & 0.48 & 0.70 & 0.80 & 0.64 \\
\hline SMDA & 0.39 & 0.89 & 0.65 & 0.76 & 0.74 & 0.74 & - & 0.48 & 0.67 & 0.51 \\
\hline SI & -0.05 & 0.08 & 0.23 & 0.14 & 0.05 & 0.23 & 0.10 & - & 0.50 & 0.96 \\
\hline VC & 0.06 & 0.36 & 0.78 & 0.81 & 0.31 & 0.83 & 0.50 & 0.88 & - & 0.90 \\
\hline GC & 0.04 & 0.14 & 0.30 & 0.21 & 0.10 & 0.29 & 0.16 & 0.97 & 0.49 & - \\
\hline
\end{tabular}


Table 11 Correlation coefficients for the $60 \times 60$ instances

\begin{tabular}{|c|c|c|c|c|c|c|c|c|c|c|}
\hline & CEN & RG & MAD & VAR & MD & AD & SMDA & SI & VC & GC \\
\hline CEN & - & 0.65 & 0.38 & 0.45 & 0.34 & 0.44 & 0.62 & 0.06 & 0.28 & 0.13 \\
\hline RG & 0.54 & - & 0.49 & 0.61 & 0.83 & 0.59 & 0.91 & 0.33 & 0.52 & 0.39 \\
\hline MAD & 0.30 & 0.28 & - & 0.82 & 0.24 & 0.92 & 0.38 & 0.54 & 0.64 & 0.49 \\
\hline VAR & 0.37 & 0.42 & 0.89 & - & 0.26 & 0.99 & 0.58 & 0.49 & 0.80 & 0.49 \\
\hline MD & 0.56 & 0.92 & 0.47 & 0.59 & - & 0.58 & 0.87 & 0.35 & 0.52 & 0.40 \\
\hline AD & 0.32 & 0.35 & 0.90 & 0.95 & 0.25 & - & 0.45 & 0.53 & 0.74 & 0.53 \\
\hline SMDA & 0.52 & 0.92 & 0.60 & 0.73 & 0.79 & 0.70 & - & 0.30 & 0.55 & 0.34 \\
\hline SI & 0.06 & 0.10 & 0.22 & 0.17 & 0.08 & 0.20 & 0.12 & - & 0.32 & 0.91 \\
\hline VC & 0.17 & 0.32 & 0.75 & 0.78 & 0.24 & 0.79 & 0.46 & 0.80 & - & 0.81 \\
\hline GC & 0.11 & 0.15 & 0.23 & 0.21 & 0.11 & 0.22 & 0.16 & 0.92 & 0.38 & - \\
\hline
\end{tabular}

First, the correlation coefficients are decreasing when instances with a bigger amount of demand points and facilities are considered. In some cases, we find negative values for $r_{u}^{v}$ (e.g., SI with CEN) or very low. In particular, this happens when considering the CEN measure that presents very low values for $r_{u}^{v}$. Indeed, when dealing with bigger instances the CEN measure takes into account only one of the distances so it is not completely representing an equal distribution for all the demand points. Second, we noticed that when optimizing SI and GC even if we have high values for $r_{u}^{v}$ we do not have correspondent high values for $r_{v}^{u}$. For example, if we consider the measure SI, when we optimise SI the $r_{u}^{S I}$ are very low when $u$ is any of the other measures apart from the other two normalized measures VC and GC. Instead, the $r_{S I}^{v}$ are all very high apart from the measure CEN. Thus, optimizing SI or GC we get solutions that are not very much correlated with the not normalized measures, but these solutions are instead correlated with the normalized measures. Third, we pointed out that optimizing not normalized measures we found solutions that are correlated even to the not normalized ones, even if the values of correlation coefficient are not among the highest ones. 
Moreover, increasing the size of the instances the $r_{u}^{v}$ values decrease. Finally, the other normalized measure VC, instead, has high values of correlation coefficient with all the measures even for medium size instances.

\section{Conclusions}

In this paper we analysed a specific class of Facility Location Problems in which equality measures are used as objective function. The analysis of the literature about these problems shows a relevant interest of the scientific community with the proposals of models and methods oriented to solve FLPs by adopting a variety of equality measures as objective functions. However, it is not often clear which criteria drive the choice of a specific measure among those proposed in the literature. For this reason, we have proposed an empirical analysis based on the solution of a general mathematical formulation of a location problem of $p$ facilities with an equality measure as objective function, which we solved considering each equality measure. In order to investigate about similarities existing between pairs of equality measures, two indicators were introduced: the number of occurrences in which, solving the instance with two different equality measures, we obtained the same optimal solution, and a correlation coefficient measure able to capture similarities between pairs of equality measures. The analysis of these indicators has fostered some interesting indications about the characteristics of equality measures and which one to choose. In particular, the Center measure presents very low correlations with all the other measures. The reason seems to be that is the only measure that considers not the whole distribution of demand points but only the most disadvantageous user. This insight seems to be confirmed by the Range measure that presents low value of correlation given that takes into account only two users. Furthermore, a fundamental distinction should be done between normalized and not normalized measures, as they generally found distinct solutions and also with low level of 
correlation in value. The not normalized measures are faster to compute and it is possible to compute them also for bigger instances. For this reason, they can be adopted when a lot of users are considered or, for smaller instances, when a solution is required in short computational times. For the same reason these measures seem to be appropriate even in a multiobjective problem when the complexity of the problem requires to obtain solutions in fast way. For example, the CEN measure it is among the most common one and with Cplex is possible to solve instances up to 200 demand points (Dantrakul et al. 2014). Nevertheless, depending on the application the decision maker could choose to adopt measures for which algorithms and their complexity are known (Mesa et al. 2003).

On the other hand, the normalised measures can be adopted for small size problems or when facilities that will operate in the long term needs to be located. Furthermore, given their high level of correlation they are very much consistent and decision makers can use them as a tool to show the consistency of the decision.

Moreover, we have verified that increasing the number of demand points the measures are less correlated in value. In addition, the measures SI and GC seems to be not correlated to the other measures, while VC seems to keep the trend even for bigger instances.

Additionally, we have analysed the measures LOGVAR, THE and ATK for small instances. These measures are extremely complex to calculate and for their nature it is not possible to introduce them in a combinatorial optimization model. In particular, the measure THE seems to be very promising with very high correlation values and it could be worth further investigating the implication of its adoption in the location context.

These first significant results coming from an extensive computational study, should be confirmed by additional experiments, also considering different versions of FLPs, in order to attempt to generalize the conclusions. Experiments could be carried on bigger instances if specialised algorithms will be used or a more efficient formulation will be proposed. 


\section{Appendix}

We propose the linear version of the model (1) through (7) for measures SI, VC and GC using the procedure introduced by Chang (2001).

To the notation introduced in Section 2 we add:

t a positive continuous variable;

$\mathrm{u}_{\mathrm{ij}} \quad$ a positive variable defined $\forall \mathrm{i} \in \mathrm{I}, \mathrm{j} \in \mathrm{J}$;

The formulation of the linear mathematical model for measure SI is:

$\min \sum_{\mathrm{i} \in \mathrm{I}}\left|\sum_{j \in J} d_{i j} u_{i j}-\sum_{i \in I, \quad j \in J} \frac{d_{i j} u_{i j}}{N}\right|$

subject to:

$\sum_{\mathrm{j} \in \mathrm{J}} \mathrm{x}_{\mathrm{ij}}=1$

$\forall \mathrm{i} \in \mathrm{I}$

$y_{j}-x_{i j} \geq 0$

$\forall \mathrm{i} \in \mathrm{I}, \forall \mathrm{j} \in \mathrm{J}$

$\sum_{\mathrm{j} \in \mathrm{J}} \mathrm{y}_{\mathrm{j}}=\mathrm{p}$

$\sum_{j \in J} d_{i j} x_{i j}+\left(M-d_{i j}\right) y_{j} \leq M$

$\forall \mathrm{i} \in \mathrm{I}, \forall \mathrm{j} \in \mathrm{J}$

$\left(\sum_{j \in J, \quad i \in I} d_{i j} u_{i j}\right) / N=1$

$u_{i j} \geq M\left(x_{i j}-1\right)+t$

$\forall \mathrm{i} \in \mathrm{I}, \forall \mathrm{j} \in \mathrm{J}$

$u_{i j} \leq M\left(1-x_{i j}\right)+t$

$\forall \mathrm{i} \in \mathrm{I}, \forall \mathrm{j} \in \mathrm{J}$

$\mathrm{u}_{\mathrm{ij}} \leq \mathrm{Mx}_{\mathrm{ij}}$

$\forall \mathrm{i} \in \mathrm{I}, \forall \mathrm{j} \in \mathrm{J}$ 

$\mathrm{x}_{\mathrm{ij}}=0 / 1$
$\forall \mathrm{i} \in \mathrm{I}, \forall \mathrm{j} \in \mathrm{J}$
$y_{j}=0 / 1$
$\forall \mathrm{j} \in \mathrm{J}$
$\mathrm{u}_{\mathrm{ij}} \geq 0$
$\forall \mathrm{i} \in \mathrm{I}, \forall \mathrm{j} \in \mathrm{J}$
$t>0$

To the previous notation we add:

$\mathrm{l}_{\mathrm{cd}} \quad$ a variable defined $\forall \mathrm{c} \in \mathrm{I}, \mathrm{d} \in \mathrm{I}$

The formulation of the linear mathematical model for measure GC is:

$\min \sum_{c \in I} l_{c d}$

subject to:
$l_{c d} \geq \sum_{j \in J} d_{c j} u_{c j}-\sum_{j \in J} d_{d j} u_{d j}$
$\forall \mathrm{d} \in \mathrm{I}, \forall \mathrm{d} \in \mathrm{I}$
$\mathrm{l}_{\mathrm{cd}} \geq-\left(\sum_{\mathrm{j} \in \mathrm{J}} \mathrm{d}_{\mathrm{cj}} \mathrm{u}_{\mathrm{cj}}-\sum_{\mathrm{j} \in \mathrm{J}} \mathrm{d}_{\mathrm{dj}} \mathrm{u}_{\mathrm{dj}}\right)$
$\forall \mathrm{d} \in \mathrm{I}, \forall \mathrm{d} \in \mathrm{I}$
$\sum_{\mathrm{j} \in \mathrm{J}} \mathrm{x}_{\mathrm{ij}}=1$
$\forall \mathrm{i} \in \mathrm{I}$
$y_{j}-x_{i j} \geq 0$
$\forall \mathrm{i} \in \mathrm{I}, \forall \mathrm{j} \in \mathrm{J}$
$\sum_{\mathrm{j} \in \mathrm{J}} \mathrm{y}_{\mathrm{j}}=\mathrm{p}$
$\sum_{j \in J} d_{i j} x_{i j}+\left(M-d_{i j}\right) y_{j} \leq M$
$\forall \mathrm{i} \in \mathrm{I}, \forall \mathrm{j} \in \mathrm{J}$
$\left(\sum_{j \in J,} i \in I d_{i j} u_{i j}\right) / N=1$
$u_{i j} \geq M\left(x_{i j}-1\right)+t$
$\forall \mathrm{i} \in \mathrm{I}, \forall \mathrm{j} \in \mathrm{J}$
$u_{i j} \leq M\left(1-x_{i j}\right)+t$
$\forall \mathrm{i} \in \mathrm{I}, \forall \mathrm{j} \in \mathrm{J}$
$\mathrm{u}_{\mathrm{ij}} \leq \mathrm{Mx}_{\mathrm{ij}}$
$\forall \mathrm{i} \in \mathrm{I}, \forall \mathrm{j} \in \mathrm{J}$ 


$\begin{array}{ll}\mathrm{x}_{\mathrm{ij}}=0 / 1 & \forall \mathrm{i} \in \mathrm{I}, \forall \mathrm{j} \in \mathrm{J} \\ \mathrm{y}_{\mathrm{j}}=0 / 1 & \forall \mathrm{j} \in \mathrm{J} \\ \mathrm{u}_{\mathrm{ij}} \geq 0 & \forall \mathrm{i} \in \mathrm{I}, \forall \mathrm{j} \in \mathrm{J} \\ \mathrm{l}_{\mathrm{ij}} \geq 0 & \forall \mathrm{i} \in \mathrm{I}, \forall \mathrm{j} \in \mathrm{J} \\ \mathrm{t}>0 & \end{array}$

The formulation of the linear mathematical model for measure VC is:

$$
\min \sum_{\mathrm{i} \in \mathrm{I}}\left(\sum_{\mathrm{j} \in \mathrm{J}} \mathrm{u}_{\mathrm{ij}} \mathrm{d}_{\mathrm{ij}}^{2} \mathrm{x}_{\mathrm{ij}}-2 \times \sum_{\mathrm{j} \in \mathrm{J}} \mathrm{d}_{\mathrm{ij}} \mathrm{x}_{\mathrm{ij}}+\sum_{\mathrm{i} \in \mathrm{I}, \mathrm{j} \in \mathrm{J}} \mathrm{d}_{\mathrm{ij}} \mathrm{x}_{\mathrm{ij}}\right)
$$

subject to:

$\sum_{\mathrm{j} \in \mathrm{J}} \mathrm{x}_{\mathrm{ij}}=1$

$\forall \mathrm{i} \in \mathrm{I}$

$\mathrm{y}_{\mathrm{j}}-\mathrm{x}_{\mathrm{ij}} \geq 0$

$\forall i \in I, \forall j \in J$

$\sum_{\mathrm{j} \in \mathrm{J}} \mathrm{y}_{\mathrm{j}}=\mathrm{p}$

$\sum_{j \in J} d_{i j} x_{i j}+\left(M-d_{i j}\right) y_{j} \leq M$

$\forall \mathrm{i} \in \mathrm{I}, \forall \mathrm{j} \in \mathrm{J}$

$\left(\sum_{\mathrm{j} \in \mathrm{J}, \mathrm{i} \in \mathrm{I}} \mathrm{d}_{\mathrm{ij}} \mathrm{u}_{\mathrm{ij}}\right) / \mathrm{N}=1$

$$
\begin{array}{ll}
\mathrm{u}_{\mathrm{ij}} \geq \mathrm{M}\left(\mathrm{x}_{\mathrm{ij}}-1\right)+\mathrm{t} & \forall \mathrm{i} \in \mathrm{I}, \forall \mathrm{j} \in \mathrm{J} \\
\mathrm{u}_{\mathrm{ij}} \leq \mathrm{M}\left(1-\mathrm{x}_{\mathrm{ij}}\right)+\mathrm{t} & \forall \mathrm{i} \in \mathrm{I}, \forall \mathrm{j} \in \mathrm{J} \\
\mathrm{u}_{\mathrm{ij}} \leq \mathrm{Mx}_{\mathrm{ij}} & \forall \mathrm{i} \in \mathrm{I}, \forall \mathrm{j} \in \mathrm{J} \\
\mathrm{x}_{\mathrm{ij}}=0 / 1 & \forall \mathrm{i} \in \mathrm{I}, \forall \mathrm{j} \in \mathrm{J} \\
\mathrm{y}_{\mathrm{j}}=0 / 1 & \forall \mathrm{j} \in \mathrm{J} \\
\mathrm{u}_{\mathrm{ij}} \geq 0 & \forall \mathrm{i} \in \mathrm{I}, \forall \mathrm{j} \in \mathrm{J}
\end{array}
$$




\section{References}

Barbati, M., and C. Piccolo. (2016). "Equality measures properties for location problems". Optimization Letters, 10(5), 903-920.

Bruno, G., A. Genovese and A. Sgalambro. (2010). "An Agent-Based framework for modeling and solving location problems". TOP, 18, 81-96.

Burkey, M. L., Bhadury, J., and H. A. Eiselt. (2012). "A location-based comparison of health care services in four US states with efficiency and equity". Socio-Economic Planning Sciences, 46(2), 157-163.

Chang, C.T. (2001). "On the polynomial mixed 0-1 fractional programming problem". European Journal of Operational Research, 131, 224-227.

Dantrakul, S., Likasiri, C., and R. Pongvuthithum. (2014). "Applied p-median and p-center algorithms for facility location problems". Expert Systems with Applications, 41(8), 3596-3604.

Drezner, T. (2004). "Location of casualty collection points". Environment and Planning C: Government and Policy, 22, 899-912.

Drezner, T., Drezner, Z., and S. Salhi. (2006). "A multi-objective heuristic approach for the casualty collection points location problem". Journal of the Operational Research Society, 57(6), 727-734.

Drezner, T., and Z. Drezner. (2007). "Equity Models in Planar Location". Computational Management Science, 4, 1-16.

Drezner, T., Drezner, Z., and J. Guyse. (2009). "Equitable service by a facility: Minimizing the Gini coefficient". Computers and Operations Research, 36, 3240-3246.

Drezner, T., Drezner, Z., and B. Hulliger. (2014). "The Quintile Share Ratio in location analysis". European Journal of Operational Research. 238, 166-174.

Eiselt, H.A., and G. Laporte. (1995). "Objectives in Location Problems". In: Facility Location: A Survey of Applications and Methods, 151-180, edited by Z. Drezner. Berlin: Springer-Verlag.

Erkut, E. (1993). "Inequality measures for location problems". Location Science, 1, 199-217. 
Erkut, E., Karagiannidis, A., Perkoulidis, G., and S. A. Tjandra. (2008). "A multicriteria facility location model for municipal solid waste management in North Greece". European Journal of Operational Research, 187(3), 1402-1421.

Espejo, I., A. Marín, J. Puerto, A. Rodríguez-Chía. (2009). "A comparison of formulations and solution methods for the minimum-envy location problem". Computers and Operations Research, 36, 1966-1981.

Foul, A. (2006). "A 1-center problem on the plane with uniformly distributed demand points". Operations Research Letters, 34(3), 264-268.

Geyer, S. (2010). "Income, income, or income? The effects of different income measures on health in a national survey". Journal of Epidemiology \& Community Health, 65:491496.

Hakimi, S. L. (1965). "Optimum distribution of switching centers in a communication network and some related graph theoretic problems". Operations Research, 13, 462-475.

Halpern, J., and O. Maimon (1983). "Accord and Conflict Among Several Objectives in Locational Decisions on Tree Networks". In Locational Analysis of public Facilities, 301-314, edited by J.F. Thisse and H.G. Zoller. Amsterdam: 1rth Holland Publ. Co.

Hodgart, R.L. (1980). "Optimizing Access to Public services: a Review of Problems, Models and Methods of Locating Central Facilities". Progress in Human Geography, 2:17-48.

$\mathrm{Hu}, \mathrm{Y}$., and P.C. Loizou. (2008). "Evaluation of objective quality measures for speech enhancement". IEEE Transactions on audio, speech, and language processing, 16(1), 229-238.

Kalcsics, J., Nickel, S., Puerto, J., A. M. and Rodríguez-Chía. (2015). "Several 2-facility location problems on networks with equity objectives". Networks, 65(1), 1-9.

Kawachi, I., and B.P. Kennedy. (1997). "The relationship of income inequality to mortality: does the choice of indicator matter?". Social science \& medicine, 45(7), 1121-1127.

Lei, T. L. (2016). "Designing Reliable Center Systems: A Vector Assignment Center Location Problem". Geographical Analysis, 48(4), 411-426.

López-de-los-Mozos, M.C., and J.A. Mesa. (2001). "The maximum absolute deviation measure in location problems on networks". European Journal of Operational Research, 135, 184-194.

López-de-los-Mozos, M. C., Mesa, J. A., and J. Puerto. (2008). "A generalized model of equality measures in network location problems". Computers \& Operations Research, 35, 651-660. 
Marsh, M.T., and D.A. Schilling. (1994). "Equity measurement in facility location analysis: A review and framework". European Journal of Operations Research, 74, 1-17.

Mesa, J. A., Puerto, J., and A. Tamir. (2003). "Improved algorithms for several network location problems with equality measures". Discrete applied mathematics, 130(3), 437-448.

Miyagawa, M. (2014). "Distribution of the sum of distances to the first and second nearest facilities". Geographical Analysis, 46(3), 321-333.

Rajagopalan, H. K., Saydam, C., and J. Xiao. (2008). "A multiperiod set covering location model for dynamic redeployment of ambulances". Computers \& Operations Research, 35(3), 814-826.

Romero, N., Nozick, L. K., and N. Xu. (2016). "Hazmat facility location and routing analysis with explicit consideration of equity using the Gini coefficient". Transportation research part E: logistics and transportation review, 89, 165-181.

Smith, H. K., Harper, P. R., and C. N. Potts. (2013). "Bicriteria efficiency/equity hierarchical location models for public service application". Journal of the Operational Research Society, 64(4), 500-512. 